\title{
Application of ion-exchange resin beads to produce magnetic adsorbents
}

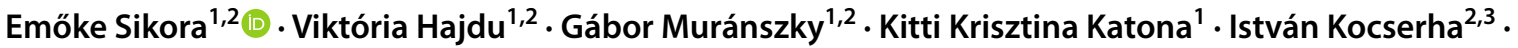 \\ Toshiyuki Kanazawa $^{4} \cdot$ Béla Fiser $^{1,2,5} \cdot$ Béla Viskolcz $^{1,2} \cdot$ László Vanyorek $^{1,2}$
}

Received: 17 February 2020 / Accepted: 23 September 2020 / Published online: 3 October 2020

(c) The Author(s) 2020

\begin{abstract}
Heavy metal ions are among the most dangerous contaminants, which can cause serious health problems. In this work, ionexchange resin beads were used as supports for magnetite $\left(\mathrm{Fe}_{3} \mathrm{O}_{4}\right)$ synthesis to produce heavy metal adsorbents which can be easily separated by magnetic field. The first step of the magnetite preparation was the replacement of hydrogen ions with $\mathrm{Fe}^{2+}$ and $\mathrm{Fe}^{3+}$ ions on the sulfonic acid groups of the resin. In the second step, magnetite particle formation was induced by coprecipitating the iron ions with sodium hydroxide. The regeneration of the ion-exchange resin was also carried out by using sodium hydroxide. SEM images verified that relatively large magnetite crystal particles (diameter $=100-150 \mathrm{~nm}$ ) were created. The ion-exchange effect of the prepared magnetic adsorbent was also confirmed by applying $\mathrm{Cu}^{2+}, \mathrm{Ni}^{2+}, \mathrm{Pb}^{2+}$ and $\mathrm{Cd}^{2+}$ ions in adsorption experiments.
\end{abstract}

Keywords Heavy metal ion removal $\cdot$ Magnetite $\cdot$ Adsorption capacity $\cdot$ Langmuir constant

\section{Introduction}

Over the last century, there has been an unsustainable increase in human-caused environmental pollution. Our soil, air and water are increasingly polluted (Nica et al. 2019). Heavy metal ions are among the most dangerous contaminants, which can cause serious health problems (Järup 2003). Metals such as arsenic, lead, copper, cadmium,

Electronic supplementary material The online version of this article (https://doi.org/10.1007/s11696-020-01376-y) contains supplementary material, which is available to authorized users.

Emőke Sikora

emoke.sikora@gmail.com

1 Institute of Chemistry, University of Miskolc, Miskolc-Egyetemváros, Hungary

2 Higher Education Industry Cooperation Centre, University of Miskolc, Miskolc, Hungary

3 Institute of Ceramics and Polymer Engineering, University of Miskolc, Miskolc, Hungary

4 JEOL (EUROPE) SAS, 1 Allée de Giverny, Croissy-sur-Seine, France

5 Ferenc Rákóczi II. Transcarpathian Hungarian Institute, Beregszász, Transcarpathia, Ukraine nickel, mercury, chromium, cobalt, and zinc are dangerous not just for humans, but can be harmful to all living organism (Masindi and Muedi 2018). The widespread metal ion pollution forced the European Council to issue a directive (98/83/EC) about the quality requirements and ion concentration limits of drinking water $(<5 \mu \mathrm{g} / \mathrm{L}$ of $\mathrm{Cd},<2 \mathrm{mg} / \mathrm{L}$ of $\mathrm{Cu},<20 \mu \mathrm{g} / \mathrm{L}$ of $\mathrm{Ni}$ and $<10 \mu \mathrm{g} / \mathrm{L}$ of $\mathrm{Pb})$. Numerous studies have been dealing with the removal of heavy metal ions from water, providing more and better alternatives to solve this ecological problem (Anuja Ashok Bhatt 2015; Carolin et al. 2017; Kobielska et al. 2018; Siyal et al. 2018). The developed technologies are based on various procedures such as membrane filtration (Altalhi et al. 2016), chemical precipitation (Charerntanyarak 1999), ion exchange (Pansini et al. 1991), electrochemical treatment (Janssen and Koene 2002), and adsorption.

Adsorption techniques have been of great interest, because compared with other methods, it has significant advantages including simple design, easy operation, and high separation efficiency (Afroze and Sen 2018). A wide range of systems have been tested as adsorbents, including biopolymers (Huang et al. 1996; Wan Ngah et al. 2011) and waste materials (Orhan and Büyükgüngör 1993) or synthetic materials like ion-exchange resins (Alexandratos 2009). Industrial-scale applications are also known with 
ion-exchange resin, activated carbon and silica gel (Karnib et al. 2014), but there are promising materials which have only been tested on laboratory scale, i.e., graphene microbots (Vilela et al. 2016), or different nanomaterials (Wang et al. 2012) and nanocomposites (Sharma et al. 2014). There are also many interesting new experiments on the subject, where for example pyrolyzed camel bones (Alqadami et al. 2018) or watermelon rind extract-capped $\mathrm{ZnS}$ nanoparticles (Devasangeeth et al. 2018) were used.

Excellent adsorption capacity has been achieved with Amberlite resin for $\mathrm{Cu}, \mathrm{Zn}, \mathrm{Ni}, \mathrm{Cd}, \mathrm{Pb}$ (Demirbas et al. 2005) and Hg (Naushad et al. 2016). It has been proved with column experiments that the Amberlite IR-120 resin is selective for $\mathrm{Pb}^{2+}$ in quantitative binary separation (Naushad and Alothman 2015). In this work, a synthetic ion-exchange resin-based system has been applied as adsorbent and combined with magnetic properties.

The adsorption capacity of magnetic materials has been investigated in several studies (Ozay et al. 2009)(Ge et al. 2012). The magnetites have also been studied and $8.67 \mathrm{mg} / \mathrm{g}$ and $18.61 \mathrm{mg} / \mathrm{g}$ adsorption has been reached for $\mathrm{Cr}$ and $\mathrm{Cu}$ ions, respectively, by using a mixed solution of $80 \mathrm{mg} / \mathrm{L}$ $\mathrm{Cr}(\mathrm{VI})$ and $\mathrm{Cu}$ (II) (Zhang et al. 2020). In a similar study, $9.72 \mathrm{mg} / \mathrm{g}$ was measured as the maximum adsorption capacity for arsenic removal (Darezereshki et al. 2018). In another case, the total amount of lead was removed from an aqueous medium by using magnetite $(50 \mathrm{mg} / \mathrm{L}$ with $20 \mathrm{mg} / \mathrm{L}$ adsorbent dose) (Bagbi et al. 2016). In each of these studies, the adsorption capacity of magnetite was a result of the $\mathrm{OH}$ groups which were present on the surface and initiated electrostatic interaction with the metal ions. $\mathrm{Hu}$ and his colleagues created magnetite nanoparticles for $\mathrm{Cr}(\mathrm{VI})$ removal and achieved $11.23 \mathrm{mg} / \mathrm{g}$ maximum capacity $(\mathrm{Hu}$ et al. 2004). Activated carbon containing magnetic alginate beads (AC-MAB) were tested against activated carbon to compare the adsorption capacities of the systems and it was found that the AC-MAB was $>62$ times better adsorbent for methylene blue (MB) (Rocher et al. 2008). Magnetic chitosan/clay beads were also tested for MB dye removal and a maximum uptake of $82 \mathrm{mg} / \mathrm{g}$ was achieved (Bée et al. 2017). Magnetite particles are frequently used, because they are biocompatible, inexpensive, chemically stable and their surface modification is easy (Davarpanah et al. 2015; Vojoudi et al. 2017).

The general procedure of heavy metal removal has two steps, first, the precipitation settling of the metal hydroxide is carried out, which is followed by the thickening or filtration of the sludge (Feng et al. 2000). This method has several disadvantages including the potential incomplete precipitation, chemical instability of the precipitates and formation of large volumes of sludge which can be difficult to filter (Feng et al. 2000). These disadvantages can be avoided by applying ion-exchange resins. However, the system filled with ion-exchange resins will initiate backpressure into the columns and limit the flow rate and the processing throughput of industrial wastewater (Zhang et al. 2019). Therefore, a suspended solid adsorbent which can be easily removed from the aqueous medium is preferred. Such adsorbent could be a resin combined with magnetic properties in fluidized beds (Feng et al. 2000). By using a magnetic adsorbent, the separation from the aqueous medium by applying magnetic field is not just easier, but also faster, selective and efficient (Xu et al. 2010; Sharma et al. 2018).

In our work, the excellent adsorption properties of ionexchange resins with the magnetic properties of magnetite have been combined, using a simple preparation method. Ion-exchange resin beads were applied for magnetite $\left(\mathrm{Fe}_{3} \mathrm{O}_{4}\right)$ synthesis, to create adsorbents (magnetic polymer beads, MPB), which can be separated by magnetic field. The ionexchange effect of the magnetic adsorbent was confirmed by $\mathrm{Cu}^{2+}, \mathrm{Ni}^{2+}, \mathrm{Pb}^{2+}$ and $\mathrm{Cd}^{2+}$ ion adsorption experiments.

\section{Experimental}

\section{Materials and methods}

Iron(III) chloride hexahydrate (VWR), iron(II) sulfate heptahydrate (Reanal) and sodium hydroxide (Sigma Aldrich) were used for magnetite synthesis. Amberlite IR120 hydrogen form ion-exchange resin (ACROS Organics MS, Table 1) was used to create the magnetic polymer beads. The synthesized MPBs have been tested in $\mathrm{Cu}^{2+} \mathrm{Ni}^{2+}, \mathrm{Pb}^{2+}$ and $\mathrm{Cd}^{2+}$ adsorption experiments by using copper(II) chloride (Aldrich), nickel(II) nitrate hexahydrate (Reanal), lead(II) nitrate (Reanal) and cadmium(II) nitrate (Reanal). In every experiment, eight diluted samples $(0.5-10 \mathrm{mmol} / \mathrm{L})$ were made from the corresponding stock solution $(50 \mathrm{mmol} / \mathrm{L})$. Each sample contained $0.2 \mathrm{~g}$ magnetic beads, and $50 \mathrm{~mL}$ solution with different concentrations. The samples were shaken for $2 \mathrm{~h}$ at room temperature on a horizontal shaker. The parameters were selected based on preliminary studies to achieve full adsorption isotherm.

Table 1 Amberlite IR120 hydrogen form ion-exchange resin specifications

\begin{tabular}{ll}
\hline Appearance & $\begin{array}{l}\text { Amber to } \\
\text { yellow-brown } \\
\text { beads }\end{array}$ \\
\hline Mean size & $0.620-0.830 \mathrm{~mm}$ \\
Moisture holding capacity & $53-58 \%(\mathrm{H}+)$ \\
Total volume capacity & $\geq 1.8 \mathrm{eq} / \mathrm{l}(\mathrm{H}+)$ \\
Molecular formula & $\mathrm{C}_{13} \mathrm{H}_{10} \mathrm{ClNO}_{4} \mathrm{~S}$ \\
Molecular weight & $311.736 \mathrm{~g} / \mathrm{mol}^{\circ}$ \\
\hline
\end{tabular}


The particle size and morphology were studied by highresolution scanning electron microscope (SEM) applying a JEOL JSM 7200F instrument, using carbon tape for sample preparation. The diameters of the magnetic particles were measured by using the ImageJ program. BET specific surface measurements were carried out by using $\mathrm{N}_{2}$ with a Micrometics TriStar 3000 instrument. The phase identification of the magnetic iron oxide particles was carried out by $\mathrm{X}$-ray diffraction (XRD) performed with a Rigaku Miniflex II diffractometer with $\mathrm{Cu} \mathrm{K} \alpha$ radiation source at $30 \mathrm{kV}$ and $15 \mathrm{~mA}$. The MPB samples were pulverized with a mortar before the measurement. The pure magnetite, the Amberlite IR120 hydrogen form ion-exchange resin and the synthesized MPB were also measured using a Bruker Vertex 70 Fourier-transform infrared spectroscope (FTIR, detection range was $4000-400 \mathrm{~cm}^{-1}$ at $4 \mathrm{~cm}^{-1}$ optical resolution). All samples were studied in potassium bromide pellets $(5 \mathrm{mg}$ sample in $250 \mathrm{mg} \mathrm{KBr}$ ). The concentrations of the heavy metal solutions were further analyzed by a Varian 720 ES

Table 2 ICP-OES measurement conditions and parameters

\begin{tabular}{ll}
\hline Plasma viewing mode & Axial \\
\hline Power (kW) & 1.050 \\
Plasma flow (L/min) & 15.0 \\
Auxiliary flow (L/min) & 1.50 \\
Nebulizer flow (L/min) & 0.75 \\
Replicate read time (s) & 7.00 \\
Instrument stabilization delay (s) & 25 \\
Sample uptake delay (s) & 30 \\
Pump rate (rpm) & 15 \\
Rinse time (s) & 10 \\
Measurement replicates & 3 \\
Nebulizer type & V-groove \\
Spray chamber type & Cyclonic \\
\hline
\end{tabular}

inductively coupled optical emission spectrometer (ICPOES) using Merck Certipur ICP multi-element standard IV. The measurement conditions and parameters are listed in Table 2. The detection limit for $\mathrm{Cd}, \mathrm{Pb}, \mathrm{Ni}$, and $\mathrm{Cu}$ is $0.005 \mathrm{mg} / \mathrm{L}, 0.04 \mathrm{mg} / \mathrm{L}, 0.02 \mathrm{mg} / \mathrm{L}$, and $0.04 \mathrm{mg} / \mathrm{L}$, respectively, while the relative standard deviation is $<5 \%$.

\section{Synthesis of the magnetic adsorbents}

In first step, the Amberlite IR120 hydrogen form resin was dried at $120^{\circ} \mathrm{C}$ for $24 \mathrm{~h}$. Then, the aqueous solution $(25 \mathrm{~mL})$ of $\mathrm{FeSO}_{4} \cdot 7 \mathrm{H}_{2} \mathrm{O}(3.06 \mathrm{~g})$ and $\mathrm{FeCl}_{3} \cdot 6 \mathrm{H}_{2} \mathrm{O}(5.40 \mathrm{~g})$ was used for ion exchange. The dried Amberlite resin $(7.50 \mathrm{~g})$ was added to the $\mathrm{Fe}(\mathrm{II}) / \mathrm{Fe}$ (III) solution and after $2 \mathrm{~h}$ of contact time, the impregnated beads were washed with distilled water (Fig. 1). Sodium hydroxide solution $(7 \mathrm{~g} \mathrm{NaOH} / 50 \mathrm{~mL}$ water) was added to the beads, and after continuous agitation for $1 \mathrm{~h}$, the beads were separated from the alkalic media, washed and dried at $120{ }^{\circ} \mathrm{C}$ overnight. Sodium hydroxide has a dual role, on the one hand it facilitates the formation of magnetite by co-precipitation, while on the other hand, it participates in the regeneration of the ion-exchange resin (Fig. 1).

\section{Results and discussion}

\section{Analysis of the morphology of the synthesized magnetite particles}

The prepared magnetic polymer beads (MPB) have been studied by SEM and their diameter was measured and found to be between 500 and $800 \mu \mathrm{m}$ (Fig. 2a). The beads are intact, with no breakage, cracking, or damage. The surface of the MPBs are abundantly covered with welldispersed, irregular hexagonal magnetite crystals (Fig. 2b,

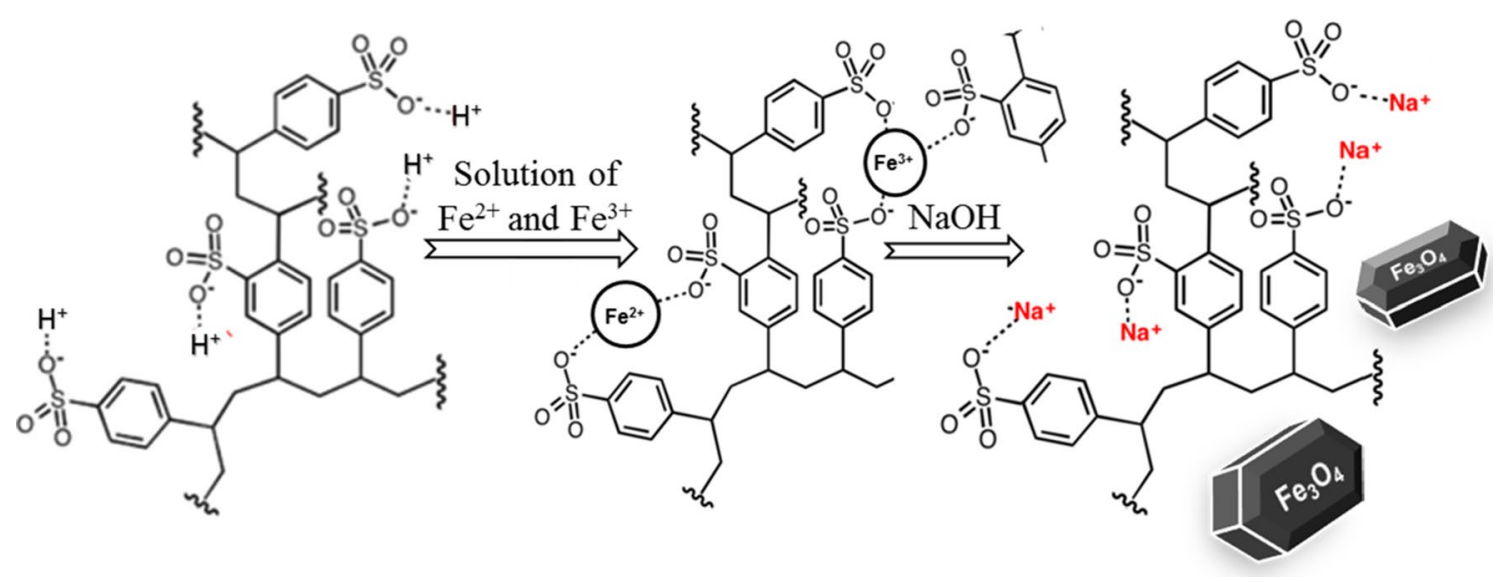

Fig. 1 Schematic representation of the formation of magnetite particles with the help of the matrix of the applied ion-exchange resin 

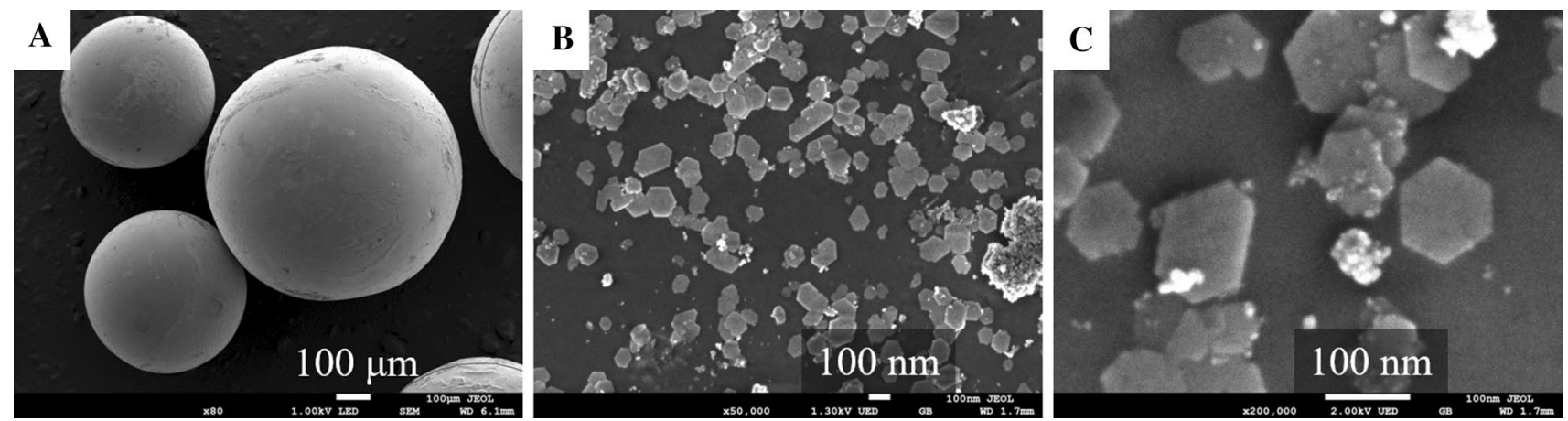

Fig. 2 SEM images of the prepared magnetic polymer beads, MPB (a), and magnetic nanoparticles on their surface (b, c)

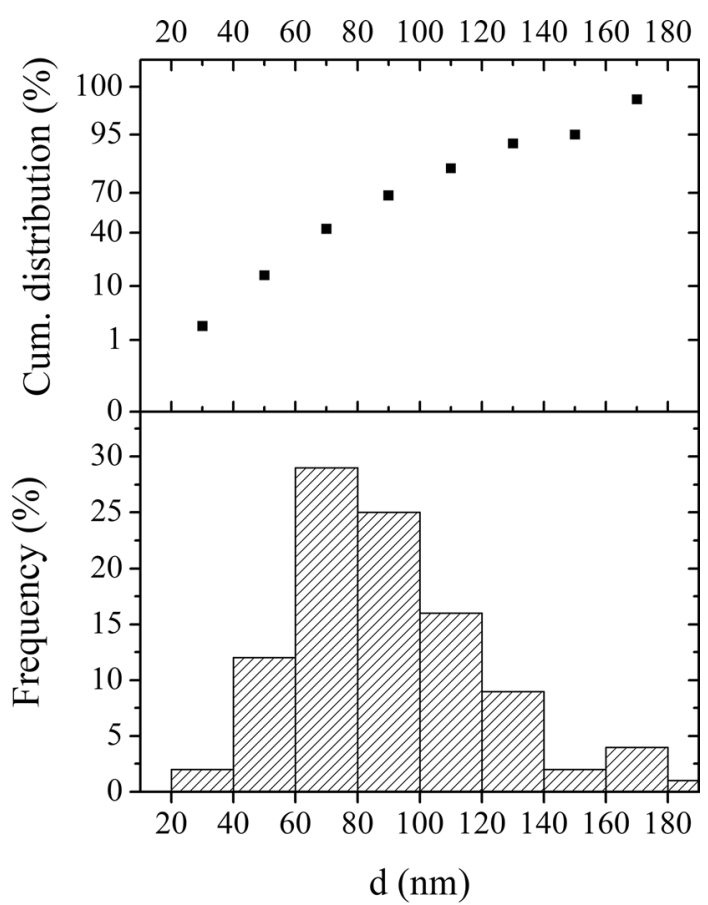

Fig. 3 Size distribution of the magnetite particles formed on the surface of the ion-exchange resin

c). The size distribution of the magnetite particles' diameter is also examined (Fig. 3.). The average diameter of the hexagons is $\sim 89 \mathrm{~nm}$.

Heavy metal adsorption experiments have been carried out and the SEM analysis have also been performed after this process. There is no significant visible difference between the images taken before or after metal removal (SI Figs. 1-5). It can be seen on the EDS spectra (SI Figs. 1-5) that the MPB sample had high sodium content before adsorption, which decreased after adsorption, and characteristic peaks of the adsorbed metals appeared. This

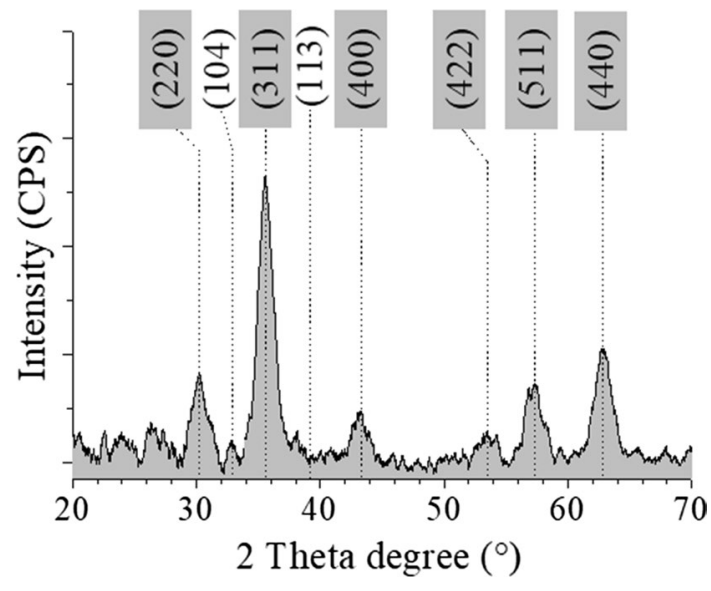

Fig. 4 XRD spectrum of the powdered magnetic polymer beads (MPB). Magnetite [gray, (220), (311), (400), (422), (511), (440)] and hematite [white, (104) and (113)] phases have been identified

suggests that the heavy metal adsorption mostly happened by ion-exchange process.

\section{Phase analysis of the magnetic iron-oxide}

Six stronger diffraction peaks were identified on the XRD spectrum of the powdered MPBs at the $2 \theta$ of $30^{\circ}, 36^{\circ}, 43^{\circ}$, $53^{\circ}, 57^{\circ}$ and $63^{\circ}$ (Fig. 4), which correspond to the (220), (311), (400), (422), (511), and (440) crystalline planes of magnetite phase $\left(\mathrm{Fe}_{3} \mathrm{O}_{4}\right)$, respectively (Kazeminezhad and Mosivand 2014). Two additional weaker peaks have also been found at $33^{\circ}$ and $39^{\circ} 2 \theta$, which can be associated with the (104) and (113) planes and indicates the presence of an $\alpha-\mathrm{Fe}_{2} \mathrm{O}_{3}$, hematite phase (Chernyshova et al. 2007).

\section{FTIR measurements of the magnetic adsorbent}

The FTIR spectra of pure Amberlite IR120 hydrogen form resin, magnetite and the final MPB were measured and 


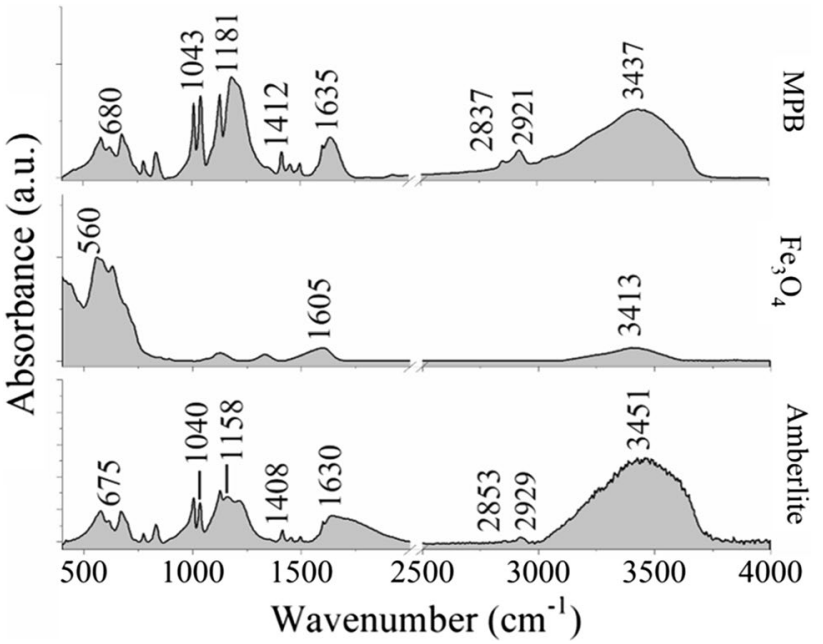

Fig. 5 FTIR spectrum of the prepared magnetic polymer beads (MPB, top) compared to magnetite (middle) and Amberlite IR120 hydrogen form ion-exchange resin (bottom)

compared (Fig. 5). The widest band appeared between 3000 and $3700 \mathrm{~cm}^{-1}$ and it can be associated with the vibration of $\mathrm{O}-\mathrm{H}$ groups in the systems (Fig. 5). It is important that $\mathrm{OH}$ groups have been detected on the surface of the magnetite, because their presence could promote adsorption. The aliphatic $\mathrm{C}-\mathrm{H}$ stretching can also be identified at $2853 \mathrm{~cm}^{-1}$ and $2929 \mathrm{~cm}^{-1}$ (Singare et al. 2011). The presence of $\mathrm{C}=\mathrm{O}$ groups is indicated by the band at $\sim 1630 \mathrm{~cm}^{-1}$ (Singare et al. 2011), while the band at $1158 \mathrm{~cm}^{-1}$ indicates that there are also $\mathrm{C}-\mathrm{N}$ groups in the samples (Haslaniza et al. 2015). The peaks observed at $675 \mathrm{~cm}^{-1}, 1040 \mathrm{~cm}^{-1}$, and $1408 \mathrm{~cm}^{-1}$ are assigned to $\mathrm{S}-\mathrm{O}$ and the stretching of $\mathrm{SO}_{3}$ and $\mathrm{O}-\mathrm{S}-\mathrm{O}$ group, respectively (Jha et al. 2009; Singare et al. 2011). The characteristic absorption band of the $\mathrm{Fe}-\mathrm{O}$ bond also appeared at $560 \mathrm{~cm}^{-1}$ (Bini et al. 2012). The groups detected in the pure materials (magnetite and Amberlite) can also be found in MPB (Fig. 5, top). There are only minor shifts in the positions of the bands, and new band has not been identified.

\section{Adsorption tests of the synthesized magnetic polymer beads}

BET specific surface area (SSA) measurements were also performed on the samples, before and after adsorption. However, in each case, the SSA was below the measurement limit, which suggests that all samples have a BET specific surface area $<1 \mathrm{~m}^{2} / \mathrm{g}$.
The heavy metal ion adsorption capacity of the synthesized MPBs was tested using $\mathrm{Cu}^{2+}, \mathrm{Ni}^{2+}, \mathrm{Pb}^{2+}$ and $\mathrm{Cd}^{2+}$. The Langmuir, the Freundlich and the Redlich-Peterson isotherm models were used to describe the equilibrium characteristics of the adsorption.

The Langmuir is defined by the following equations:

$q_{\mathrm{e}}=\frac{q_{\mathrm{m}} \times K_{\mathrm{L}} \times c_{\mathrm{e}}}{1+c_{\mathrm{e}} \times K_{\mathrm{L}}}$,

$R_{\mathrm{L}}=\frac{1}{1+K_{\mathrm{L}} \times c_{0}}$,

where $q_{\mathrm{e}}$ is the amount $(\mathrm{mg} / \mathrm{g})$, while $c_{\mathrm{e}}$ is the equilibrium concentration of the heavy metal ion in the solution $(\mathrm{mg} / \mathrm{L})$, $q_{\mathrm{m}}$ is the maximum sorption capacity $\left(\mathrm{mg} / \mathrm{g}\right.$ ) and $K_{\mathrm{L}}$ is the Langmuir equilibrium constant $(\mathrm{L} / \mathrm{mg}) . K_{\mathrm{L}}$ and $q_{\mathrm{m}}$ can be calculated with nonlinear regression. $R_{\mathrm{L}}$ is the separation factor without unit and $c_{\mathrm{o}}$ is the initial heavy metal concentration $(\mathrm{mg} / \mathrm{L})$.

The Freundlich isotherm can be described as follows:

$q_{\mathrm{e}}=K_{\mathrm{F}} \times c_{\mathrm{e}}^{\frac{1}{n}}$,

where $K_{\mathrm{F}}$ and $n$ are constants.

The Redlich-Peterson (Eq. 4.) is a hybrid isotherm model that combines the Freundlich and the Langmuir models with three parameters (Al-Ghouti and Da' ana 2020):

$q_{\mathrm{e}}=\frac{K_{\mathrm{R}} \times c_{\mathrm{e}}}{1+a_{\mathrm{R}} \times c_{\mathrm{e}}^{\mathrm{b}}}$,

where $K_{\mathrm{R}}, a_{\mathrm{R}}$ and $\mathrm{b}$ are constants. Previous studies have shown that it is more accurate than the Langmuir and the Freundlich models, because it contains three tuning parameters (Kumara et al. 2014).

For each heavy metal ions, eight dilution points have been applied during the measurements. By comparing the three fitted isotherms (Table 3), it was found that the correlation coefficients $\left(R^{2}\right)$ are close to 1 in each case, and the isotherms fit well to the results, but as it was expected, the most accurate is the Redlich-Peterson isotherm. However, the Langmuir model will be used in the following discussion (Fig. 6) as it is the most commonly applied isotherm in similar studies and the difference between the two fits (Langmuir vs Redlich-Peterson) is not significant.

According to the results, the highest $q_{\mathrm{m}}$ was obtained in the case of $\mathrm{Pb}^{2+}$ ions $(3.64 \mathrm{mmol} / \mathrm{g}$ ), while the highest affinity $\left(K_{\mathrm{L}}\right)$ was observed for nickel $0.57 \mathrm{~L} / \mathrm{mg}$. The separation factors indicate strong interactions between the heavy metal ions and the MPB adsorbent and show that the isotherm type is favorable $\left(0<R_{\mathrm{L}}<1\right)$ (Kocaoba 2007)(Tan et al. 2012). 
Table 3 The calculated adsorption parameters

\begin{tabular}{|c|c|c|c|c|c|c|c|c|c|c|c|}
\hline & \multicolumn{4}{|l|}{ Langmuir } & \multicolumn{2}{|c|}{ Freundlich } & \multicolumn{5}{|c|}{ Redlich-Peterson } \\
\hline & $q_{\mathrm{m}}(\mathrm{mmol} / \mathrm{g})$ & $K_{\mathrm{L}}(\mathrm{L} / \mathrm{mg})$ & $R_{\mathrm{L}}$ range & $R^{2}$ & $\overline{K_{\mathrm{F}}}$ & $n$ & $R^{2}$ & $K_{\mathrm{R}}$ & $a_{\mathrm{R}}$ & $b$ & $R^{2}$ \\
\hline $\mathrm{Pb}^{2+}$ & $3.64 \pm 0.02$ & 0.19 & $0.002-0.023$ & 0.9989 & 290.96 & 14.73 & 0.9913 & 5599.99 & 19.13 & 0.93 & 0.9999 \\
\hline $\mathrm{Cu}^{2+}$ & $2.21 \pm 0.04$ & 0.27 & $0.005-0.048$ & 0.9989 & 85.91 & 10.12 & 0.9997 & 186.68 & 1.97 & 0.92 & 0.9999 \\
\hline $\mathrm{Ni}^{2+}$ & $1.89 \pm 0.04$ & 0.57 & $0.003-0.027$ & 0.9998 & 84.38 & 17.68 & 0.9919 & 79.18 & 0.75 & 0.99 & 0.9998 \\
\hline $\mathrm{Cd}^{2+}$ & $1.79 \pm 0.02$ & 0.31 & $0.003-0.035$ & 0.9997 & 125.02 & 10.20 & 0.9980 & 190.00 & 1.30 & 0.93 & 0.9999 \\
\hline
\end{tabular}

Fig. $6 \mathrm{Cu}^{2+}(\mathbf{a}), \mathrm{Cd}^{2+}(\mathbf{b}), \mathrm{Pb}^{2+}$ (c), and $\mathrm{Ni}^{2+}(\mathbf{d})$ heavy metal ion adsorption capacity of the synthesized magnetic ionexchange beads
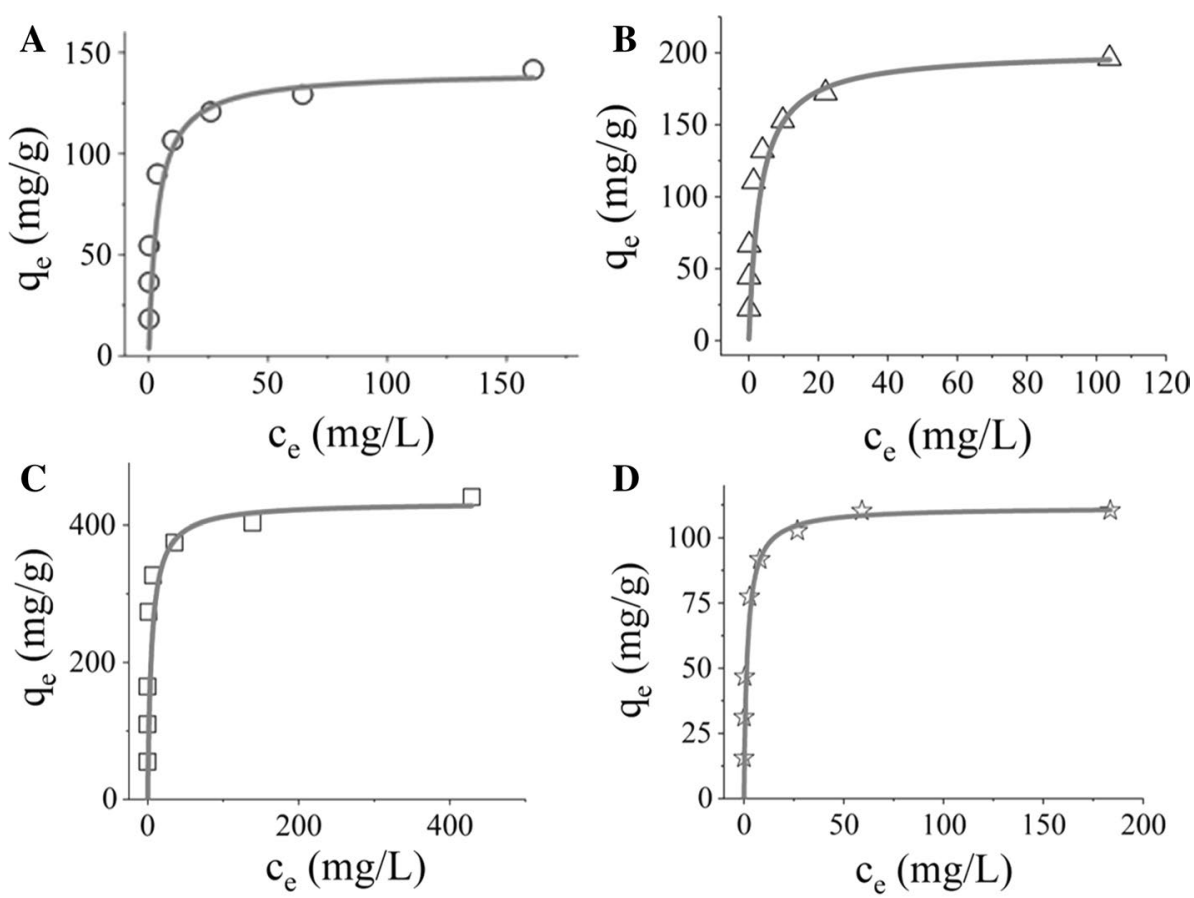

$O \mathrm{Cu}^{2+} \triangle \mathrm{Cd}^{2+} \square \mathrm{Pb}^{2+} \underset{3}{2} \mathrm{Ni}^{2+}$

Computational and experimental adsorption data shows that the dry resin's adsorption capacity for $\mathrm{Pb}^{2+}$ and $\mathrm{Ni}^{2+}$ ions is $5.56 \mathrm{meq} / \mathrm{g}$ (Carmona et al. 2008), while for $\mathrm{Cu}^{2+}$ and $\mathrm{Cd}^{2+}$ ions it is $5.0 \mathrm{meq} / \mathrm{g}$ (Valverde et al. 2002). Thus, by adding magnetite to the system, the adsorption capacity of the resin slightly reduced in case of $\mathrm{Cu}^{2+}, \mathrm{Ni}^{2+}$, and $\mathrm{Cd}^{2+}$ ions, but improved for $\mathrm{Pb}^{2+}$. However, the trend in the adsorption capacity $\mathrm{Pb}^{2+}>\mathrm{Cu}^{2+}>\mathrm{Ni}^{2+}>\mathrm{Cd}^{2+}$ is similar to a previous study where pure resin was tested as adsorbent (Naushad and Alothman 2015).

The synthesized MPB's adsorption parameters and capacity have also been compared to other magnetic adsorbents from the literature (Table 4). It can be seen that the prepared MPB has excellent adsorption capacity, and it is the best in almost every aspect.

After the adsorption tests, the magnetic beads were removed easily from the aqueous media by using a magnet (Fig. 7).

\section{Conclusions}

In our work, magnetic polymer beads were successfully created starting from Amberlite IR120 ion-exchange resin beads. The diameter of the magnetic polymer beads is in a range of $500-800 \mu \mathrm{m}$. The surface of the polymer beads is covered with well-dispersed, hexagonal magnetite crystals. The presence of magnetite particles was verified by XRD measurements. The heavy metal ion adsorption capacity of the synthesized MPB was tested using $\mathrm{Cu}^{2+}, \mathrm{Ni}^{2+}, \mathrm{Pb}^{2+}$ and $\mathrm{Cd}^{2+}$. The developed MPB is a very efficient adsorbents, especially in the case of $\mathrm{Pb}$ removal. Besides its adsorption capacity, it is easy to handle and due to its magnetic property, it can be easily removed from the medium by applying magnetic field. Furthermore, it has higher adsorption capacity in almost all cases for the studied heavy metal ions compared to other magnetic adsorbents from the literature. 

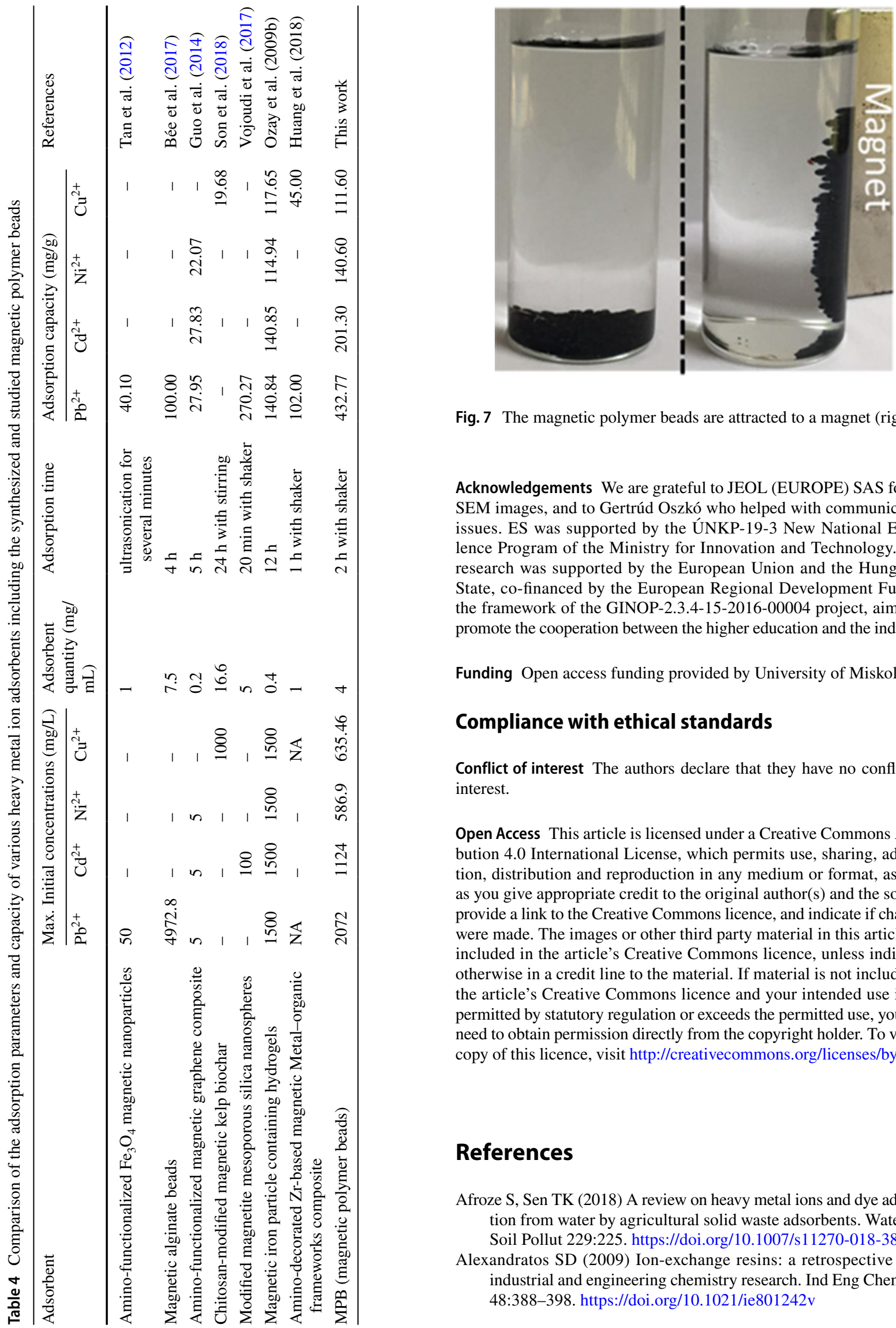

Fig. 7 The magnetic polymer beads are attracted to a magnet (right)

Acknowledgements We are grateful to JEOL (EUROPE) SAS for the SEM images, and to Gertrúd Oszkó who helped with communication issues. ES was supported by the UNKP-19-3 New National Excellence Program of the Ministry for Innovation and Technology. This research was supported by the European Union and the Hungarian State, co-financed by the European Regional Development Fund in the framework of the GINOP-2.3.4-15-2016-00004 project, aimed to promote the cooperation between the higher education and the industry.

Funding Open access funding provided by University of Miskolc.

\section{Compliance with ethical standards}

Conflict of interest The authors declare that they have no conflict of interest.

Open Access This article is licensed under a Creative Commons Attribution 4.0 International License, which permits use, sharing, adaptation, distribution and reproduction in any medium or format, as long as you give appropriate credit to the original author(s) and the source, provide a link to the Creative Commons licence, and indicate if changes were made. The images or other third party material in this article are included in the article's Creative Commons licence, unless indicated otherwise in a credit line to the material. If material is not included in the article's Creative Commons licence and your intended use is not permitted by statutory regulation or exceeds the permitted use, you will need to obtain permission directly from the copyright holder. To view a copy of this licence, visit http://creativecommons.org/licenses/by/4.0/.

\section{References}

Afroze S, Sen TK (2018) A review on heavy metal ions and dye adsorption from water by agricultural solid waste adsorbents. Water Air Soil Pollut 229:225. https://doi.org/10.1007/s11270-018-3869-z

Alexandratos SD (2009) Ion-exchange resins: a retrospective from industrial and engineering chemistry research. Ind Eng Chem Res 48:388-398. https://doi.org/10.1021/ie801242v 
Al-Ghouti MA, Da' ana DA (2020) Guidelines for the use and interpretation of adsorption isotherm models: a review. J Hazard Mater 393:122383

Alqadami AA, Khan MA, Otero M et al (2018) A magnetic nanocomposite produced from camel bones for an efficient adsorption of toxic metals from water. J Clean Prod 178:293-304. https://doi. org/10.1016/J.JCLEPRO.2018.01.023

Altalhi T, Mezni A, Aldalbahi A et al (2016) Fabrication and characterisation of sulfur and phosphorus (S/P) co-doped carbon nanotubes. Chem Phys Lett 658:92-96. https://doi.org/10.1016/j.cplet t.2016.06.028

Anuja Ashok Bhatt MK (2015) Removal of heavy metals from water $(\mathrm{Cu}$ and $\mathrm{Pb})$ using household waste as an adsorbent. J Bioremed Biodegrad. https://doi.org/10.4172/2155-6199.1000269

Bagbi Y, Sarswat A, Mohan D et al (2016) Lead (Pb2+) adsorption by monodispersed magnetite nanoparticles: surface analysis and effects of solution chemistry. J Environ Chem Eng 4:4237-4247. https://doi.org/10.1016/j.jece.2016.09.026

Bée A, Obeid L, Mbolantenaina R et al (2017) Magnetic chitosan/ clay beads: a magsorbent for the removal of cationic dye from water. J Magn Magn Mater 421:59-64. https://doi.org/10.1016/J. JMMM.2016.07.022

Bini RA, Marques RFC, Santos FJ et al (2012) Synthesis and functionalization of magnetite nanoparticles with different amino-functional alkoxysilanes. J Magn Magn Mater 324:534-539. https:// doi.org/10.1016/J.JMMM.2011.08.035

Carmona M, Warchoł J, De Lucas A, Rodriguez JF (2008) Ionexchange equilibria of $\mathrm{Pb} 2+, \mathrm{Ni} 2+$, and $\mathrm{Cr} 3+$ ions for $\mathrm{H}+$ on amberlite IR-120 resin. J Chem Eng Data 53:1325-1331. https:// doi.org/10.1021/je8000552

Carolin CF, Kumar PS, Saravanan A et al (2017) Efficient techniques for the removal of toxic heavy metals from aquatic environment: a review. J Environ Chem Eng 5:2782-2799. https://doi. org/10.1016/j.jece.2017.05.029

Charerntanyarak L (1999) Heavy metals removal by chemical coagulation and precipitation. Water Sci Technol 39:135-138. https://doi. org/10.1016/S0273-1223(99)00304-2

Chernyshova IV, Hochella MF Jr, Madden AS (2007) Size-dependent structural transformations of hematite nanoparticles. 1. Phase transition. Phys Chem Chem Phys 9:1736. https://doi.org/10.1039/ b618790k

Darezereshki E, Darban AK, Abdollahy M, Jamshidi-Zanjani A (2018) Influence of heavy metals on the adsorption of arsenate by magnetite nanoparticles: kinetics and thermodynamic. Environ Nanotechnol Monit Manag 10:51-62. https://doi.org/10.1016/j. enmm.2018.04.002

Davarpanah M, Ahmadpour A, Rohani Bastami T (2015) Preparation and characterization of anion exchange resin decorated with magnetite nanoparticles for removal of p-toluic acid from aqueous solution. J Magn Magn Mater 375:177-183. https://doi. org/10.1016/j.jmmm.2014.09.065

Demirbas A, Pehlivan E, Gode F et al (2005) Adsorption of $\mathrm{Cu}(\mathrm{II})$, $\mathrm{Zn}(\mathrm{II}), \mathrm{Ni}(\mathrm{II}), \mathrm{Pb}$ (II), and $\mathrm{Cd}$ (II) from aqueous solution on Amberlite IR-120 synthetic resin. J Colloid Interface Sci 282:20-25. https://doi.org/10.1016/J.JCIS.2004.08.147

Devasangeeth SD, Balaji GL, Lakshmipathy R (2018) Multi metal ion sorption capacity of watermelon rind extract capped $\mathrm{ZnS}$ nanoparticles. Int J Pure Appl Math 118:1-12

Feng D, Aldrich C, Tan H (2000) Removal of heavy metal ions by carrier magnetic separation of adsorptive particulates. Hydrometallurgy 56:359-368. https://doi.org/10.1016/S0304-386X(00)00085 $-2$

Ge F, Li M-M, Ye H, Zhao B-X (2012) Effective removal of heavy metal ions $\mathrm{Cd} 2+, \mathrm{Zn} 2+, \mathrm{Pb} 2+, \mathrm{Cu} 2+$ from aqueous solution by polymer-modified magnetic nanoparticles. J Hazard
Mater 211-212:366-372. https://doi.org/10.1016/J.JHAZM AT.2011.12.013

Guo X, Du B, Wei Q et al (2014) Synthesis of amino functionalized magnetic graphenes composite material and its application to remove $\mathrm{Cr}(\mathrm{VI}), \mathrm{Pb}(\mathrm{II}), \mathrm{Hg}(\mathrm{II}), \mathrm{Cd}(\mathrm{II})$ and $\mathrm{Ni}(\mathrm{II})$ from contaminated water. J Hazard Mater 278:211-220. https://doi. org/10.1016/j.jhazmat.2014.05.075

Haslaniza H, Wan Yaacob WA, Zubairi SI, Maskat MY (2015) Potential of amberlite IRA 67 resin for deacidification of organic acids in noni juice. Der Pharma Chem 7:62-69

$\mathrm{Hu}$ J, Lo IMC, Chen G (2004) Removal of Cr(VI) by magnetite. Water Sci Technol 50:139-146. https://doi.org/10.2166/wst.2004.0706

Huang C, Chung Y-C, Liou M-R (1996) Adsorption of $\mathrm{Cu}(\mathrm{II})$ and $\mathrm{Ni}(\mathrm{II})$ by pelletized biopolymer. J Hazard Mater 45:265-277. https ://doi.org/10.1016/0304-3894(95)00096-8

Janssen LJ, Koene L (2002) The role of electrochemistry and electrochemical technology in environmental protection. Chem Eng J 85:137-146. https://doi.org/10.1016/S1385-8947(01)00218-2

Järup L (2003) Hazards of heavy metal contamination. Br Med Bull 68:167-182. https://doi.org/10.1093/bmb/ldg032

Jha MK, Van Nguyen N, Lee-chun J et al (2009) Adsorption of copper from the sulphate solution of low copper contents using the cationic resin Amberlite IR 120. J Hazard Mater 164:948-953. https://doi.org/10.1016/j.jhazmat.2008.08.103

Karnib M, Kabbani A, Holail H, Olama Z (2014) Heavy metals removal using activated carbon, silica and silica activated carbon composite. Energy procedia. Elsevier Ltd, Amsterdam, pp $113-120$

Kazeminezhad I, Mosivand S (2014) Phase transition of electrooxidized $\mathrm{Fe}_{3} \mathrm{O}_{4}$ to $\gamma$ and $\alpha-\mathrm{Fe}_{2} \mathrm{O}_{3}$ nanoparticles using sintering treatment. Acta Phys Pol A 125:1210-1214. https://doi.org/10.12693 /APhysPolA.125.1210

Kobielska PA, Howarth AJ, Farha OK, Nayak S (2018) Metal-organic frameworks for heavy metal removal from water. Coord Chem Rev 358:92-107. https://doi.org/10.1016/J.CCR.2017.12.010

Kocaoba S (2007) Comparison of Amberlite IR 120 and dolomite's performances for removal of heavy metals. J Hazard Mater 147:488-496. https://doi.org/10.1016/j.jhazmat.2007.01.037

Kumara NTRN, Hamdan N, Petra MI et al (2014) Equilibrium isotherm studies of adsorption of pigments extracted from Kuduk-kuduk (Melastoma malabathricum L.) pulp onto $\mathrm{TiO}_{2}$ nanoparticles. J Chem. https://doi.org/10.1155/2014/468975

Masindi V, Muedi KL (2018) Environmental Contamination by heavy metals. In: Heavy Metals. InTech

Naushad M, Alothman ZA (2015) Separation of toxic Pb2+ metal from aqueous solution using strongly acidic cation-exchange resin: analytical applications for the removal of metal ions from pharmaceutical formulation. Desalin Water Treat 53:2158-2166. https:// doi.org/10.1080/19443994.2013.862744

Naushad M, Vasudevan S, Sharma G et al (2016) Adsorption kinetics, isotherms, and thermodynamic studies for $\mathrm{Hg} 2+$ adsorption from aqueous medium using alizarin red-S-loaded amberlite IRA-400 resin. Desalin Water Treat 57:18551-18559. https://doi. org/10.1080/19443994.2015.1090914

Nica A, Popescu A, Ibanescu D-C (2019) Human influence on the climate system. Curr Trends Nat Sci 8:209-215

Orhan Y, Büyükgüngör H (1993) The removal of heavy metals by using agricultural wastes. Water Sci Technol 28:247-255. https://doi. org/10.2166/wst.1993.0114

Ozay O, Ekici S, Baran Y et al (2009) Removal of toxic metal ions with magnetic hydrogels. Water Res 43:4403-4411. https://doi. org/10.1016/J.WATRES.2009.06.058

Pansini M, Colella C, De Gennaro M (1991) Chromium removal from water by ion exchange using zeolite. Desalination 83:145-157. https://doi.org/10.1016/0011-9164(91)85091-8 
Rocher V, Siaugue J-M, Cabuil V, Bee A (2008) Removal of organic dyes by magnetic alginate beads. Water Res 42:1290-1298. https ://doi.org/10.1016/j.watres.2007.09.024

Sharma G, Pathania D, Naushad M, Kothiyal NC (2014) Fabrication, characterization and antimicrobial activity of polyaniline $\mathrm{Th}(\mathrm{IV})$ tungstomolybdophosphate nanocomposite material: efficient removal of toxic metal ions from water. Chem Eng J 251:413-421. https://doi.org/10.1016/j.cej.2014.04.074

Sharma M, Kalita P, Senapati KK, Garg A (2018) Study on magnetic materials for removal of water pollutants. In: Emerging pollutants-some strategies for the quality preservation of our environment. InTech

Singare PU, Lokhande RS, Madyal RS (2011) Thermal degradation studies of some strongly acidic cation exchange resins. Open J Phys Chem 1:45-54. https://doi.org/10.4236/ojpc.2011.12007

Siyal AA, Shamsuddin MR, Khan MI et al (2018) A review on geopolymers as emerging materials for the adsorption of heavy metals and dyes. J Environ Manag 224:327-339. https://doi. org/10.1016/J.JENVMAN.2018.07.046

Son EB, Poo KM, Mohamed HO et al (2018) A novel approach to developing a reusable marine macro-algae adsorbent with chitosan and ferric oxide for simultaneous efficient heavy metal removal and easy magnetic separation. Bioresour Technol 259:381-387. https://doi.org/10.1016/j.biortech.2018.03.077

Tan Y, Chen M, Hao Y (2012) High efficient removal of Pb(II) by amino-functionalized $\mathrm{Fe}_{3} \mathrm{O}_{4}$ magnetic nano-particles. Chem Eng J 191:104-111. https://doi.org/10.1016/j.cej.2012.02.075

Valverde JL, De Lucas A, González M, Rodríguez JF (2002) Equilibrium data for the exchange of $\mathrm{Cu} 2+, \mathrm{Cd} 2+$, and $\mathrm{Zn} 2+$ ions for $\mathrm{H}+$ on the cationic exchanger Amberlite IR-120. J Chem Eng Data 47:613-617. https://doi.org/10.1021/je010299g

Vilela D, Parmar J, Zeng Y et al (2016) Graphene-based microbots for toxic heavy metal removal and recovery from water. Nano Lett 16:2860-2866. https://doi.org/10.1021/acs.nanolett.6b00768
Vojoudi H, Badiei A, Bahar S et al (2017) A new nano-sorbent for fast and efficient removal of heavy metals from aqueous solutions based on modification of magnetic mesoporous silica nanospheres. J Magn Magn Mater 441:193-203. https://doi. org/10.1016/J.JMMM.2017.05.065

Wan Ngah WS, Teong LC, Hanafiah MAKM (2011) Adsorption of dyes and heavy metal ions by chitosan composites: a review. Carbohydr Polym 83:1446-1456. https://doi.org/10.1016/j.carbp ol.2010.11.004

Wang X, Gou Y, Yang L et al (2012) Nanomaterials as sorbents to remove heavy metal ions in wastewater treatment. J Environ Anal Toxicol. https://doi.org/10.4172/2161-0525.1000154

$\mathrm{Xu}$ Y, Chen L, Wang $\mathrm{H}$ et al (2010) Preparation of magnetic strong cation exchange resin for the extraction of melamine from egg samples followed by liquid chromatography-tandem mass spectrometry. Anal Chim Acta 661:35-41. https://doi.org/10.1016/j. aca.2009.12.002

Zhang T, Dai S, Mo S et al (2019) Magnetic ion-exchange resins for superconducting magnetic separation system: kinetics, isotherm, and mechanism of heavy metals removal magnetic ion-exchange resins for superconducting magnetic separation system: kinetics, isotherm, and mechanism of. Mater Sci Eng. https://doi. org/10.1088/1757-899X/490/2/022015

Zhang J, Lin S, Han M et al (2020) Adsorption properties of magnetic magnetite nanoparticle for coexistent $\mathrm{Cr}(\mathrm{VI})$ and $\mathrm{Cu}(\mathrm{II})$ in mixed solution. Water 12:446. https://doi.org/10.3390/w12020446

Publisher's Note Springer Nature remains neutral with regard to jurisdictional claims in published maps and institutional affiliations. 